To cite this article: Sarı N. Erol Ç, Hızel K. Yoğun bakım ünitelerinde santral venöz kateter ilişkili kan dolaşımı infeksiyonu sıklığı, mikrobiyolojik etkenleri, antibiyotiklere duyarlılıkları ve risk faktörlerinin belirlenmesi. Turk J Clin Lab 2021; 4: 404-408.

\title{
Yoğun bakım ünitelerinde santral venöz kateter ilişkili kan dolaşımı infeksiyonu sıklığı, mikrobiyolojik etkenleri, antibiyotiklere duyarlılıkları ve risk faktörlerinin belirlenmesi
}

\section{Determination of incidence, causative agents, antimicrobial susceptibilities, and risk factors of central venous catheter-related bloodstream infections in intensive care units}

\author{
Nuran SARI*1 $⿴$, Çiğdem EROL ${ }^{1} \square$, Kenan $\mathrm{HIZEL}^{2}$ 回
}

'Başkent Üniversitesi Tıp Fakültesi, Enfeksiyon Hastalıkları ve Klinik Mikrobiyoloji Anabilim Dalı, Ankara/TÜRKiYE ${ }^{2}$ Gazi Üniversitesi Tıp Fakültesi, Enfeksiyon Hastalıkları ve Klinik Mikrobiyoloji Anabilim Dalı, Ankara/TÜRKiYE

\section{öz}

Amaç: Santral venöz kateterler (SVK), yoğun bakım ünitelerinde hastaların tedavisi ve izlemi için sık kullanılan aletlerdir. Santral venöz kateter ilişkili infeksiyonları belirlemek, uygun ampirik antibiyotik tedavisi açısından yol gösterici olmak ve sonraki çalışmalar için karşılaştırılabilir veri sağlamak amaçlanmıştır.

Gereç ve Yöntemler: Yoğun bakım ünitelerinde, aktif prospektif sürveyans kapsamında takip edilen ve Centers for Disease Control and Prevention (CDC) kriterlerine göre SVK ilişkili kan dolaşımı infeksiyonu tanısı konulan hastaların, retrospektif olarak SVK kullanım oranları, kateter ilişkili kan dolaşımı infeksiyon (KiKDi) hızları, mikrobiyolojik etkenleri, antibiyotiklere duyarlılık sonuçları ve risk faktörleri değerlendirilmiştir. Veriler SPSS 17.0 istatistik paket programına kaydedilerek, analiz edilmiştir.

Bulgular: Santral kateter kullanım oranı \%48 ve infeksiyon hızı 8,07 olarak saptanmıştı. İzole edilen 72 patojenin, 28' i gram pozitif (\% 28,9), 31'i gram negatif ( $\% 43,6)$, 13'ü mantar (\%18,5) olup, koagülaz negatif stafilokok (\%22), Candida spp. $(\% 18,8)$ Acinetobacter spp. $(\% 16,6)$ en sık saptanan etkenler olmuştur. Koagülaz negatif stafilokoklarda metisilin direnci $\% 75$, S. aureus' da $\% 67$ saptanmıştır.

Sonuç: Gereksiz santral kateter kullanımından kaçınılması, endikasyon kalkınca çıkarılması ve altta yatan hastalıkların tedavi edilmesi ile KiKDi oranlarında azalma sağlanabileceği düşünülmektedir.

Anahtar Kelimeler: Santral venöz kateter; infeksiyon; yoğun bakım ünitesi 


\section{ABSTRACT}

Aim: Central venous catheters (CVCs) are widely utilized for patient therapy and monitoring in intensive care units. Its goal is to identify infections caused by central venous catheters, to recommend appropriate empirical antibiotic therapy in intensive care units, and to offer comparable data for future investigations.

Material and Methods: Patients who were followed up in intensive care units as part of an active prospective surveillance program and were found to have CVC-related bloodstream infections according to Centers for Disease Control and Prevention (CDC) criteria were spared. Retrospectively, the rates of catheter-related bloodstream infections (CRBSI), CVC use, microbiological agents, antibiotic sensitivity, and risk factors were evaluated. The data was analyzed and recorded using the SPSS 17.0 statistical package application.

Results: The rate of central venous catheter use was 0.48 and the rate of central catheter-related infection was determined as 8.07 . The 72 pathogens identified were 28 gram-positive (28.9\%), 31 gram-negative (43.6\%) and 13 fungi (18.5\%) and coagulase-negative staphylococci (22\%), Candida spp. (18.8\%), Acinetobacter spp. (16.6\%) were the most commonly found agents. The methicillin resistance was detected in $75 \%$ of coagulase-negative staphylococci and $67 \%$ of S. aureus strains.

Conclusion: It is believed that reducing the incidence of CRBSI can be achieved by avoiding needless CVCs use, removing it when the indication is no longer needed, and treating the underlying medical conditions.

Keywords: Central venous catheter; infection; intensive care unit

\section{Giriş}

Santral venöz kateterler (SVK) SIVI, elektrolit tedavisi, kan ürünleri verilmesi, antibiyotikve kemoterapi uygulanması, hemodinamik izlem gibi amaçlarla özellikle yoğun bakım ünitelerinde sıklıkla kullanılmaktadır. Kullanım sıklığının artmasına paralel olarak alınan tüm önlemlere rağmen santral venöz kateter ilişkili infeksiyonların sıklığında artış söz konusudur [1]. Uzun süreli kateter kullanımında bakteriyemi, kateter giriş yeri infeksiyonları, septik trombofilebit, endokardit, diğer metastatik infeksiyonlar (akciğer apsesi, beyin apsesi, osteomiyelit, endoftalmit vb.) gibi ciddi komplikasyonlar gelişebilmektedir [2,3]. Amerika Birleşik Devletleri (ABD) yoğun bakım ünitelerinde katetere bağıı bakteriyemi riski 5.3/1000 kateter günüdür ve her yıl yaklaşık 80.000 SVK ilişkili bakteriyemi (SVKIB) meydana gelmektedir [4]. Bunun yanında kateter infeksiyonları hastalara ve kurumlara, hastanede kalış süresinin uzaması, bakım hizmetleri ve ek tedaviler dolayısıyla mali yükler getirmektedir $[5,6]$.

Santral venöz kateterler nozokomiyal damar içi infeksiyonlarının en sık nedenidir ve günümüzde nozokomiyal infeksiyonlar arasında kan dolaşımı infeksiyonları \%14' lük sıklık ile üçüncü sırada yer almaktadır $[7,8]$. Sürveyans kapsamında toplanan verilerle bazal hastane infeksiyonu hızlarının ve zaman içinde meydana gelen değişikliklerin saptanması, infeksiyon hızlarındaki anlamlı artışların fark edilmesi, kontrol önlemlerinin alınması ve bu önlemlerin etkinliğinin araştıııması mümkün olmaktadır $[9,10]$.

\section{Gereç ve Yöntemler}

Yoğun bakım ünitelerinde aktif prospektif sürveyans kapsamında izlenen hastaların verileri 1 Ocak 2008-1 Ocak 2009 tarihleri arasında retrospektif olarak değerlendirilmiştir. Nozokomiyal KiKDi tanımlamaları için CDC kriterleri, SVK kullanım oranı ve santral kateter ilişkili infeksiyon hızı (SKiH) hesaplamalarında National Nosocomial İnfections Surveillance System (NNIS) verileri kullanılmıştır. Yoğun bakım ünitelerinde takip edilen, bakteriyemi düşünülen hastalardan uygun koşullarda santral ve periferik kan kültürleri istenmiştir. Enfekte santral venöz kateterlerin 4-5 cm uç kısmı steril şartlarda Maki ve ark. tanımladığı yöntem uyarınca semikantitatif olarak kanlı agar ve EMB agara ekilmiştir [11,12]. Mikroorganizmaların antibiyotik duyarlılıkları Clinical and Laboratory Standarts Institute (CLSI) standartlarına uygun olarak Kirby-Bauer Disk Difüzyon yöntemi ile çalışılmıştır [13]. Kateter kan kültüründe, perifer kan kültürüne göre en az 2 saat önce üreme olması, pasaj plaklarında aynı etkenin 5-10 kat fazla üreme olması veya kateter ucu kültüründe Maki yöntemi ile semikantitatif olarak 15 cfu üzerinde üremesi olması ile kateter ilişkili kan dolaşımı infeksiyonu için anlamlı kabul edilmiştir.

Hasta verileri retrospektif taranarak, SPSS 17.0 istatistik paket programına kaydedilerek analizleri yapılmıştır. Çalışma başlangıcında, 28 Mayıs 2007 tarihli (Karar no: 189) Etik Kurul onayı alınarak veriler toplanmaya başlamıştır. Çalışma, Helsinki Deklarasyonu 2008 prensiplerine ve iyi klinik uygulamaları kılavuzuna uygun olarak yapılmıştır. 


\section{Bulgular}

Anestezi ve Reanimasyon, Genel Cerrahi, Beyin Cerrahisi, Nöroloji, İç Hastalıkları yoğun bakım ünitesinde toplam 86 hastada 126 primer kan dolaşımı infeksiyonu tanısı konulmuştur. Primer KDi tanısı konulan 86 hastanın 50'sinde (\%58) ve toplam 126 bakteriyeminin 70'inde (\%55) KiKDi saptanmıştır. Tanı alan 50 hastanın 34'ü erkek (\%68), 16'sı (\%32) kadındı. Yaşları 19-88 arasında değişen hastaların yaş ortalaması 54 (ort. $52 \pm 16,6$ ) olarak tespit edilmiştir.

Takip edilen beş ayrı yoğun bakım ünitesinde toplam hasta günü 12,907, santral venöz kateter günü 6419, santral venöz kateter kullanım oranı 0,48 ve 1000 SVK gününe düşen santral kateter ilişkili infeksiyon hızı 8,07 olarak tespit edilmiştir.

İkisinde polimikrobiyal patojen saptanan 70 infeksiyonda izole edilen 72 etkenin 28'ini gram pozitifler $(\% 28,9)$, 31'ini gram negatifler (\%43) ve 13'ünü mantarlar (\%18) oluşturmaktaydı. Sıklık sırasına göre KiKDi etkenleri, 16 KNS $(\% 22,2)$, altı S. aureus $(\% 8,3)$, beş Enterococcus spp. $(\% 6,9)$, bir Micrococcus lueus $(\% 1,4)$ saptandı. Mantarlardan C. albicans altı $(\% 8,3)$, C.albicans dışı Candida spp., yedi $(\% 9,7)$ olarak tespit edildi. Gram negatif ve nonfermantatif etkenlerden Acinetobacter spp. 12, enterik bakteriler 10 (ikişer E.coli, Klebsiella, Enterobacter türleri ve Morganella morganii ile birer Citrobacter freundi ve Proteus türü), Pseudomonas türleri altı, Stenotrophomonas maltophilia iki ve Pantoea agglomerans bir etken olarak izole edilmiştir (Grafik 1).

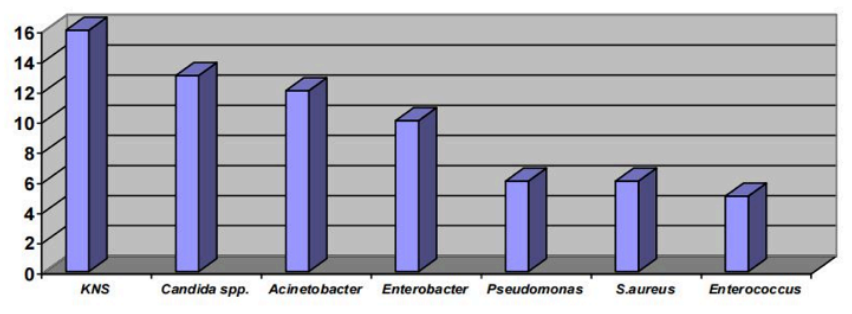

Grafik 1. Yoğun bakım ünitelerinde en sık izole edilen KIKDi etkenleri.

Antibiyotiklere direnç incelendiğinde, izole edilen altı S. aureus suşunun 4'ünde (\%66,7), 16 KNS suşunun 12'sinde (\%75) oksasilin direnci saptanmıştır, glikopeptid direncine rastlanmamıştır. Enterik bakterilerde sefepim ve seftazidime \%35-45, seftriaksona, sefotaksime, kinololara \%55 direnç saptanmıştır. Acinetobacter spp.'de kolistimetat sodyum, amikasin ve netilmisin dışındaki antibiyotiklere \%50 üzerinde direnç saptanmıştır. Benzer şekilde Pseudomonasspp'deamikasin, kolistimetatsodyum, karbapenem dışında tüm antibiyotiklere \%50 üzerinde, Stenotrophomonas spp.'de ise ko-trimoksazol dışındaki antibiyotiklere \%100 direnç tespit edilmiştir.

\section{Tartışma}

Nozokomiyal infeksiyonlar arasında kan dolaşımı infeksiyonları \%14'lük oran ile pnömoni ve üriner sistem infeksiyonundan sonra üçüncü sırada bildirilmektedir [5,6]. Takılan her 20 SVK'nın en az bir KIKDI'ye yol açtığı, yılda tahmini 400.000 daha fazla KiKDi görüldüğü bildirilmektedir ve primer KDİnin \% 85-90'ından sorumlu tutulmaktadırlar [14,15]. Çalışmamızda primer KDílerin (126 bakteriyemi atağı) \%55,6'sını (70 bakteriyemi atağı) KiKDi'lerin oluşturduğu saptanmıştır. Santral venöz kateterler nozokomiyal kan dolaşımı infeksiyonlarının en sık nedeni olması nedeni ile kateter ilişkili infeksiyonların hızla tanımlanması ve azaltılması için gerekli infeksiyon kontrol önlemlerin alınması önemlidir.

Yoğun bakım ünitelerinde SVK kullanım oranı ve SKIH oranlarının hangi yüzdelikte olduğunu tespit etmek ve birlikte değerlendirilmesi gerekmektedir. İnfeksiyonları azaltmak için santral kateter kullanımını veya kateter kalış süresini kısaltmak gerektiği bildirilmektedir [16]. Kullanım oranlarının azalmasına rağmen infeksiyon hızlarında artış görülmesi kateter uygulanması ve bakımı ile ilgili bazı hataların olduğunu düşündürmektedir. Ülkemizden 12 YBÜ'nin yer aldığı çok merkezli bir çalışmada SVK kullanım oranı 0,61 (çalışmamızda 0,48), SKiH ise 17,6 (çalışmamızda 8,07 ) olarak tespit edilmiştir [15]. Yine ülkemizde yapılan çalışmalarda SKIH 9,69- 10,6 olarak bildirilmektedir [17]. Avrupa'da 5 merkezde yapılan bir çalışmada SKIH'lerı 1,12- 4,2 arasında saptanmıştır [18]. Çalışmamızda SVK kullanım oranı ve SKIH değerleri ülkemiz verileri ile karşılaştırıldığında düşük görülmekle birlikte, NNIS verileri ve Avrupa verileri ile karşılaştırıldığında yüksek bulunmuştur.

En sık izole edilen etkenler koagülaz negatif stafilokok (KNS), Candida spp., Acinetobacter spp, Enterobactericeae, Pseudomonas spp. S.aureus, Enterococcus spp. olarak sıralanmaktaydı. Benzer şekilde literatür taraması yapıldığında en sık saptanan etkenler KNS, S. aureus, aerob gram negatif basiller ve kandidalar olarak bildirilmektedir [19]. Son 10 yılda KIKDI'de KNS görülme oranlarının \%10 arttığı, hastane kökenli kateterle ilişkili sepsis olgularının önemli bir kısmının hastanede çıkan KNS salgınından kaynaklandığı gösterilmiştir [20,21].

Ulusal sağlık hizmeti ilişkili sürveyans ağı 2016 verilerine göre de KNS, Enterobactericeae, Acinetobacter spp, Candida spp en sık bildirilen etkenlerdir [22]. İzole edilen 13 kandidanın altısı C. albicans (\%46.2), yedisi albicans dışı Candida (\%53.8) olarak saptanmıştır. Kateter ilişkili kandidemilerde \%73 oranında etken C. parapsilosis, \%8 C. albicans olarak bildirilmektedir [23]. Yapılan bir çalışmada SVK varlığı YBÜ'de kandidemi gelişimini altı kat, uygunsuz doz flukonazol kullanımının ise dokuz kat arttırdığı bildirilmektedir [24]. 
Yoğun bakım ünitelerinde sık ve uygunsuz antibiyotik kullanımının bir sonucu olarak çoklu ilaç direncine sahip mikroorganizmaların etken olduğu infeksiyonlar gelişmekte ve tedavilerinde güçlükler yaşanmaktadır [20,21]. Özellikle üçüncü kuşak sefalosporinler, florokinolonlar ile karbapenem türevlerinin artan uygunsuz kullanımı dirençli mikroorganizmalar ile oluşan infeksiyonların gelişiminde önemli rol oynamaktadır. Çalışmamızda KNS'de metisilin direnci \%75, S.aureus'da \%66.7 oranında saptanmıştır. Ulusal surveyans ağında KNS de \%94, S.aureus'da \%60 olarak bildirilmektedir [22]. Çalışmamızda enterik bakterilerde üçüncü kuşak sefalosporinlere direnç ortalama \%60'tır. Acinetobacter spp ve Pseudomonas spp'de sadece aminoglikozidlere \%50'nin altında direnç görülmektedir. Stenotrophomonas spp.'de ise ko-trimoksazol dışında tüm antibiyotiklere direnç saptanmıştır. Duyarlılık sonuçlarına göre ampirik tedavide stafilokoklarda yüksek metisilin direnci nedeni ile glikopeptid kullanımı, enterik bakterilerde karbapenemler, piperasilintazobaktam, sefoperazon-sulbaktam, Acinetobacter spp.'de kolistimetat sodyum, amikasin, netilmisin, Pseudomonas spp'de karbapenemler, seftazidim, amikasin, netilmisin, Stenotrophomonas' da ko-trimoksazol kullanılması uygun olacaktır. Ünitelerin direnç durumlarını bilmeleri önemlidir. Gelişmekte olan ülkelerde KIKDi hızları, gelişmiş ülkelere göre daha yüksektir. Yetersiz sayıda eğitimli sağlık personeli bulunması, çalışanların infeksiyon kontrol kurallarına uyum sorunu, infeksiyon kontrol sürveyansının hastanelerde zorunlu tutulmaması bu durumun başlıca nedenleridir. Önlem demetlerinin daha kapsamlı uygulanması yönünde bilincin oluşturulması kateter infeksiyonlarının sıfır düzeyine çekilmesinde önemli bir katkı sağlayacaktır. Uygun deri antisepsisi ve hijyen koşullarına uyulduğu takdirde katetere bağlı infeksiyon ve bakteriyemi oranları önemli ölçüde azaltılabilmektedir [24,25].

\section{Sonuç}

Yoğun bakım ünitelerinde santral kateter kullanım oranı 0.48 ve santral kateter ilişkili infeksiyon hızlarımız 8.07 gibi yüksek oranda saptanmıştır. Gereksiz santral kateter kullanımından kaçınılması, kateter takılması, pansumanı, yıkanması ve çıkarılması sırasında infeksiyon kontrol önlemlerine uyulması, kateter seti uygulaması, endikasyon ortadan kalktığında çıkarılması gibiönlemler alındığında kateter ilişkili kan dolaşımı infeksiyon hızlarında azalma sağlanacağı düşünülmektedir.

Koagülaz negatif stafilokoklar, Candida spp, Acinetobacter spp. KIKDI'lerde en sık saptanan etkenler olmuştur ve direnç oranları yüksektir. Ampirik tedavide ünitenin duyarlılık oranlarına göre en uygun tedavinin başlanması, antibiyogram sonuçlarına göre deeskalasyon yapılması direnç oranlarının azaltılması açısından önemlidir.

Çalışmamızda elde edilen yerel veriler olmasına rağmen geliştirilecek önlemler açısından karşılaştırılabilir veri oluşturabileceği düşünülmektedir.

\section{Çıkar çatışması/finansal destek beyanı}

Bu yazıdaki hiçbir yazarın herhangi bir çıkar çatışması yoktur. Yazının herhangi bir finansal desteği yoktur.

\section{Kaynaklar}

1. Centers for Disease Control and Prevention. Vital signs:central line-associated blood stream infections-United States, 2001, 2008, and 2009. MMWR Morb Mortal Wkly Rep. 11; 60: 243-8.

2. Mermel LA, Allon M, Bouza E et al. Clinical practice guidelines for the diagnosis and management of intravascular catheterrelated infection: 2009 update by the Infectious Diseases Society of America. Clin Infect Dis 2009; 49: 1-45.

3. Rosenthal VD, Maki DG, Rodrigues et al. Impact of International Nosocomial Infection Control Consortium (INICC) strategy on central line-associated bloodstream infection rates in the intensive care units of 15 developing countries. Infect Control Hosp Epidemiol 2010; 31: 1264-72.

4. O'Grady NP, Alexander M, Burns LA et al. Guidelines for the prevention of intravascular catheter-related infections. Clin Infect Dis 2011; 52: 1-32.

5. Beekman SE, Hendersan DK. Infections caused by percutaneous Intravascular devices. In: Bennett JE, Dolin R, Blaser MJ (Eds): Mandell, Dauglas, and Bennetts Principles and Practice of Infectious Disease, Eighth Edition, Philadephia, Elsevier Saunders 2015: 3309-24.

6. Glaver S, Brun-Buisson C, Infectious associated with intravascular lines, grafts and diveces. In:Cohen J, PowderlyWG, Opal SM.Infectious Disease Third Edition. China: Mosby Elsevier 2010: 491-300.

7. Cox E, Thom KA. Infectious Involving Intravascular catheters. In: Wright WF . Essentials of Clinical Infectious Diseases. New York, Demos, 2013: 70-79.

8. Weber DJ, Rutala WA. Central line-associated bloodstream infections: prevention and management. Infect Dis Clin North Am 2011; 25: 77-102.

9. Karabey S, Kaptı H. Hastane infeksiyonlarının izlemi: Sürveyans. Hastane İnfeksiyonları Kontrolü El Kitabı. Bilimsel Tıp Yayınevi Ankara 2005; 101-25. 
10. Willke A, Ateş B. Hastane infeksiyonlarının sürveyansı ve Amerikan ulusal hastane infeksiyon sürveyans sistemi. Hastane İnfeksiyonları Kontrolü El Kitabı. Bilimsel Tıp Yayınevi, Ankara 2005: 67-78.

11. Maki DG, Weise CE, Sarafin HW. A semiquantitative culture method for identifying intravenous-catheter-related Infection. N Engl J Med 1977; 296: 1305-9

12. Maki DG, Kluger DM, Crnich CJ. The risk of bloodstream infection in adults with different intravascular devices; a systematic review of 200 published prospective studies. Mayo Clin Proc 2006; 81: 1159-71

13. Clinical and Laboratory Standarts Institute. Performance Standarts for Antimicrobial Susceptibility Testing; 18th Informational Supplement: CLSI document M100-S18 (ISBN 1-56238-556-9). Clinical and Laboratory Standarts Wayne, Pennsylvania 2008; 1897-8.

14. Leblebicioğlu H, Rosenthal V.D, Arıkan A et al. Device-associated hospital acquired infection rates in Turkish intensive care units. Findings of the International Nosocomial Infection Control Consortium (INICC). J Hosp Infect 2007; 65: 251-7.

15. Rupp ME. Nosocomial bloodstream infections. Epidemiology and prevention of nosocomial infections of organ systems. Hospital Epidemiology and Infection Control. C.Glen Mayhall (ed) Third ed. Philadelphia 2004; 253-65.

16. National Nosocomial Infections Surveillance (NNIS) System Report, data summary from January 1992 through June 2004 issued October 2004. Am J Infect Control 2004; 32: 470-85.

17. İnan D, Saba R, Yalçın AN et al. Device-associated nosocomial infection rates in Turkish medical-surgical intensive care units. Infect Control Hosp Epidemiol 2006; 27: 343-8.
18. Tacconelli E, Smith G, Hieke K, Lafuma A, Bastide P. Epidemiology medical outcomes and costs of catheter-related bloodstream infections in intensive care units of four European countries literature and registry-based estimate. J Hosp Infect 2009; 72: 97-103.

19. O'Grady NP, Alexander M, Burns LAet al. Healthcare Infection Control Practices Advisory Committee. Guidelines for the prevention of intravascular catheterrelated infections. Am J Infect Control 2011; 39: 1-34.

20. Şardan YÇ, Güner R, Çakar N, Ağalar F. Damar İçi Kateter İnfeksiyonlarının Önlenmesi Kılavuzu. Hastane İnfeksiyonları Dergisi 2013; 17: 233-79.

21. Rosenthal VD, Bijie $H$, Maki DG, Mehta $Y$, Apisarnthanarak A, Medeiros EA. International Nosocomial Infection Control Consortium (INICC) report, data summary of 36 countries, for 2004-2009. Am J Infect Control 2012; 40: 396-407.

22. Hekimoğlu CH, Oku FC, Batır E. Ulusal Sağlık Hizmeti İlişkili İnfeksiyonlar Sürveyans Ağı. Etken ve Dağılımı ve Antibiyotik Direnç Raporu 2016. Ed. Şencan I Ankara 2017. 1-38.

23. Labelle A, Micek ST, Roubinian N, M Kollef. Treatment-related risk factors for hospital mortality in Candida bloodstream infections. Crit Care Med 2008; 36: 2967-72.

24. Rupp ME, Majorant D. Prevention of Vascular Catheter-Related Bloodstream Infections. Infect Dis Clin North Am 2016; 30: 853-68.

25. Ciccia M, Chakrokh R, Molinazzi D, Zanni A, Farruggia P, Sandri F. Skin antisepsis with $0.05 \%$ sodium hypochlorite before central venous catheter insertion in neonates: A 2-year single-center experience. Am J Infect Control 2018; 46: 169-72. 